\title{
DEBATES SOBRE A LEGALIZAÇÃO DA MACONHA NA SALA DE AULA: PEDAGOGIA OU APOLOGIA NA ERA DA RESISTÊNCIA?
}

\section{TALKING ABOUT CANNABIS LEGALIZATION IN THE CLASSROOM: PEDAGOGY OR APOLOGY IN THE AGE OF RESISTANCE?}

\author{
Sandra Martins ${ }^{131}$ \\ Vinicius Motta da Costa ${ }^{132}$ \\ Francisco José Figueiredo Coelho ${ }^{133}$ \\ Célia Sousa ${ }^{134}$
}

\begin{abstract}
Resumo
A maconha é uma das substâncias ilícitas mais consumidas pelo homem, desde os primórdios. Diante disso, experiências com a legalização da planta têm sido compartilhadas por diferentes países, dentre eles o Uruguai. Considerando as limitações e as potencialidades desse fenômeno social, o presente artigo descreve um relato de experiência com jovens do ensino fundamental e da educação de jovens e adultos de uma escola pública em São Gonçalo, RJ, proporcionando uma Educação sobre Drogas mais crítica e participativa. Para isso, foi realizada a exibição de reportagem e debate com questões geradoras sobre a liberação da maconha no Uruguai, articulando a possível adoção da medida no Brasil. A proposta pedagógica revelou o potencial crítico da aprendizagem sobre drogas e forneceu elementos para desmistificar as abordagens sobre maconha na sala de aula. A partir dela, aferimos que o material jornalístico associado com debates participativos corrobora, ainda que timidamente, para oferecer momentos de reflexão que estimulem o conhecimento, a troca de experiências e o entendimento recreativo e abusivo do consumo de drogas em seus contextos sociopolíticos.
\end{abstract}

Palavras-chave: Legalização da maconha. Educação sobre Drogas. Redução de Danos. Documentários na escola.

\begin{abstract}
Cannabis has been one of the most commonly used illicit substances in man since its inception. Given this, experiences with the legalization of the plant have been shared by different countries, including Uruguay. Considering the limitations and potentialities of this social question, this article describes an experience report with students in a public school, providing a more critical and participatory Drug Education. To this end, a report was
\end{abstract}

\footnotetext{
131 Jornalista e Mestre em História comparada (UFRJ). Pesquisadora colaboradora do GT interinstitucional Educação e Drogas do GIEESAA/UFRJ/UERJ. Agente voluntária no Projeto Drogas, Educação, Saúde e EJA (DESEJA). E-mail: sandra3martins@gmail.com.

132 Professor de sociologia (SEEDUC/RJ) e Mestrando em Ensino de Biociências e Saúde (FIOCRUZ). Pesquisador colaborador do GT interinstitucional Educação e Drogas do GIEESAA/UFRJ/UERJ. Coordenador pedagógico do Projeto DESEJA em Duque de Caxias. E-mail: vinimctr@gmail.com.

133 Professor de Biologia (SEEDUC/RJ) e Doutor em Ensino de Biociências e Saúde (FIOCRUZ). Coordenador do GT interinstitucional Educação e Drogas do GIEESAA/UFRJ/UERJ. Coordenador pedagógico do Projeto DESEJA em São Gonçalo. E-mail: educacaosobredrogas@gmail.com.

134 Professora adjunta do Instituto de Química (IQ) da UFRJ e Doutora em Engenharia Metalúrgica e de Materiais (COPPE/UFRJ). Coordenadora geral do GIEESAA e do Projeto DESEJA. E-mail: sousa@iq.ufrj.br.
} 
presented and a debate with generating questions about the release of marijuana in Uruguay, articulating the possible adoption of the measure in Brazil. The pedagogical proposal revealed the critical potential of drug learning and provided elements for demystifying classroom approaches to marijuana. Otherwise, it is a preventive-educational activity with great potential for the construction of young questioners and knowledge of recreational and abusive practices regarding drug use in different contexts.

Keywords: Cannabis legalization. Drug education. Harm Reduction. Documentaries at school.

\section{Introdução}

A escola é um espaço democrático e de participação popular. É um dos ambientes que proporciona aos jovens experiências críticas com assuntos referentes à formação do cidadão. Dentre esses, cabe ressaltar o tema drogas, informando e subsidiando novos olhares em relação ao uso de psicoativos, como já destacam documentos oficiais (BRASIL, 1998; 2011). Dito de outra forma, a escola pode se tornar um espaço de esclarecimentos, estimulando a redução de práticas agressivas desses jovens com seus próprios corpos e o pensamento questionador, sobretudo no contexto contemporâneo em que a vaidade, a beleza e o prazer fazem parte dos valores e dilemas juvenis.

O que temos notado da literatura do campo da Educação sobre Drogas é que há duas grandes vertentes preventivo-educativas: uma centrada na proibição e outra, que postula seu oposto, enxergando a interdição como um caminho mais agressivo do ponto de vista pedagógico. Esta última, tem como alicerce a compreensão das práticas de uso estabelecidas culturalmente - e a relação histórica milenar das pessoas com as drogas, com foco na redução de danos (RD) do uso abusivo à propriamente o não uso (COELHO, MONTEIRO, 2017; COELHO, 2019).

No primeiro plano, observamos a corrente proibicionista, voltada para o combate ao uso de substâncias, também conhecida como "Guerra às Drogas". Esta retrata um conjunto de ações que ganhou projeção na década de 1920 através de medidas restritivas sobre o consumo de algumas drogas, inclusive da Cannabis. Em particular no Brasil, Silva (2015) lembra que todo esse processo tem início em 1921, quando a primeira lei de drogas é instituída no país, numa clara adesão às linhas de ação para a política internacional proibicionista, ditada pelos norte-americanos (SILVA, 2015). 


\section{RevistAleph}

De acordo com a autora, a Lei de 1921 estabelecia penalidades para os contraventores na venda de cocaína, ópio, morfina e outros produtos. Cabe lembrar que essa lei apenas proibiu o uso das substâncias mencionadas, sem a devida prescrição médica. A venda nas farmácias para pessoas com receituário permaneceu até 1932, lembra a autora, quando o monopólio dos médicos sobre as atribuições dessas substâncias foi submetido à lei federal. Essa é também a primeira lei que faz constar a maconha na lista das substâncias proibidas (SILVA, 2015).

Autores como Hart (2014), Silva (2015) e Coelho e Monteiro (2017) aferem que tais vertentes proibicionistas preconizam projetos de assepsia social, através das políticas de saúde e educação, maximizando o estereótipo da vadiagem, em contraposição ao trabalhador cidadão (SILVA, 2015). Isso ampliou, ao longo das décadas, diferentes perseguições. Do negro pobre ao negro artista, o uso da Cannabis foi assumindo seus rótulos e intensificando estigmas, sobretudo aliados às classes econômicas menos favorecidas e aos grupos raciais (HART, 2014). O proibicionismo, aos poucos, se tornava mais agressivo e antidemocrático.

Essa prática de rotular pessoas e comportamentos, categorizando as pessoas pelas suas relações com as drogas (e por vezes unicamente pela sua cor ou gosto musical) nos parece resultar de uma desinformação social mais ampla (HART, 2014; ACSELRAD, 2015). Nem sempre o que se pensa sobre uma determinada droga é o que realmente acontece. $E$ isso resulta em uma infinidade de informações falsas (fakenews), que favorecem comportamentos de segregação (GOMES, 2018).

No plano da RD, diferente das políticas de interdição, o entendimento do consumo de drogas nem sempre é visto como nocivo. O cenário das práticas de uso e as condições de vulnerabilidade física, psíquica e emocional dos sujeitos são considerados (HART, 2014; COELHO, 2019), não se enclausurando em julgamentos de ordem moral. Nessa ótica, entendemos que todo uso de drogas pode gerar impactos orgânicos, mas não se deve descartar que as experiências de uso e abuso também se convertem em situações de aprendizagem (ACSELRAD, 2015; COELHO; MONTEIRO, 2017; COSTA, COELHO, TAMIASSOMARTINHON, SOUSA, 2019).

Considerando tais pensamentos, não enxergamos no proibicionismo uma abertura para o diálogo e para o respeito às opiniões divergentes. Qualquer experiência com drogas é vista, nesse âmbito, como algo maléfico e irresponsável. Ele sequer se importa em ouvir o 


\section{RevistAleph}

outro lado da estória. Apenas impõe. Quase sempre produz marcas irreparáveis para quem é julgado e rotulado.

A maconha é apenas uma das drogas que dissemina tais rótulos. Como visto, a partir de 1921 inicia-se uma caçada acerca dela e de outros produtos, como aponta Silva (2015). Embora considerada ilegal em muitos países, especificamente a Cannabis sativa tem várias atribuições comerciais. Desde o caule (cânhamo) ao óleo extraído de suas sementes, existem múltiplos usos consagrados na História. Os usos medicinais são os mais abundantes, devido às propriedades farmacológicas oriundos do tetrahidrocanabiol (THC) e do Canabidiol (CBD). Vale destacar a exploração na indústria farmacêutica de substâncias extraídas da Cannabis, entre elas o Bedrocan, desenvolvido pela Holanda, usada também no tratamento de glaucoma (PENHA et al., 2019).

Aqui no Brasil, em dezembro de 2019, a Agência Nacional de Vigilância Sanitária (ANVISA) incluiu a Cannabis sativa na Lista Completa das Denominações Comuns Brasileiras (DCB) sob a categoria de "planta medicinal" - uma espécie de registro com os nomes oficiais de fármacos, princípios ativos, plantas medicinais e outras substâncias de interesse médico no Brasil. E, em março de 2020, a ANVISA divulgou um regulamentação que elenca os requisitos específicos para a uso de produtos de Cannabis para fins medicinais no Brasil (BRASIL, 2020).

Essas novidades jurídicas e regulatórias sobre a Cannabis podem nos dizer muito sobre o panorama científico e clínico no país. Aliadas às perspectivas de interdição ou de redução de danos, esses conhecimentos justificam formas de pensar e agir da sociedade. Sobretudo diante do cenário de debate sobre a utilização da maconha em território brasileiro, entra em cena a seguinte discussão: as possibilidades e os anseios da possível legalização da maconha no Brasil.

$\mathrm{Na}$ contemporaneidade, os meios de comunicação - espaços simbólicos por excelência - atuam como mediadores entre os indivíduos e desses com o mundo. Cabe a eles se apropriarem e dominarem as linguagens, visto que sua participação e conquista de outros espaços dependerão cada vez mais disso. E, um desses espaços, com impacto ou convergência, é a sala de aula, onde se encontram diferentes discursos para além do pedagógico (CASTRO et al., 2007). Assim, planejar e incluir a comunicação - e sua produção - 


\section{RevistAleph}

no ambiente escolar e nas práticas curriculares é integrar às práticas educativas o estudo sistemático dos sistemas de comunicação (SOARES, 2011).

Entendemos que instaurar espaços de debate sobre a legalização das drogas por meio das mídias se integra a tais práticas educativas, veiculando múltiplas linguagens e códigos. Nesse caminho, é possível confrontar construções identitárias sobre a diversidade, rotuladas e padronizadas. Nesta interface, em especial, o conceito de mediações atua como um lugar de negociação de significados entre o produtor e o receptor dos conteúdos midiáticos. Um debate é feito de negociações, onde saber ouvir e ofertar argumentos é essencial (COELHO, MONTEIRO, 2017). Vale lembrar que tais espaços são espaços democráticos, mas revelam ideologias hegemônicas. Por isso, é preciso ter cuidado com os estereótipos naturalizados a fim de romper a perpetuação das desigualdades.

Para Malachias (2009), educadores e discentes devem participar de processos conscientes entre sua realidade e a ação das forças ideológicas que impossibilitam a assunção do respeito às diferenças étnicas e de gênero, como a desconstrução de estigmas sobre determinados temas como a droga em seu contexto sociocultural, não alimentando os prejulgamentos de pensar a palavra droga sob uma ótica proibicionista dentro do espaço escolar (COELHO; ASSIS; BARROS, 2019).

Partindo dessas premissas, temos dois aspectos importantes acerca dos debates sobre drogas nas escolas: (1) que não se educa sem haver comunicação; e (2) que um debate preventivo-educativo instituído não se faz sem o diálogo verdadeiro entre as partes. Desta forma, a comunicação e o diálogo têm natureza multidisciplinar, com potencial para manipular ou libertar e, cujas relações se complexificam ao longo das interações sociais (CASTRO et al, 2007). Por isso, entendemos que todo o cuidado nas discussões sobre drogas é fundamental, para que os argumentos não percam o objetivo da prevenção ao uso abusivo de substâncias lícitas e ilícitas.

Uma estratégia para abordar o universo que envolve a maconha é usar a produção midiática como uma aliada. Quer sejam filmes, documentários ou reportagens televisivas, essas ferramentas se colocaram como materiais apreciados pelos professores, como evidencia o estudo de Coelho, Assis e Barros (2019). Além de serem de fácil acesso pela internet, algumas dessas mídias oferecem contextos socioculturais para análise desconhecidos pelos estudantes, como é o caso da autorização de produtos à base de 


\section{RevistAleph}

maconha pela ANVISA ou experiências que países próximos tiveram ou tem com a legalização da maconha.

Para Coelho, Assis e Barros (2019), a transmissão de valores e ideologias não se dá pura e simplesmente numa via de mão única. Quer dizer, ao assistirem a tais mídias, os sujeitos refletem. Podem fazer analogias e confrontarem questões íntimas, das quais algumas - acreditamos - envolvam pensamentos precipitados e rótulos estigmatizantes e condenatórios. Em outras palavras, o mundo das imagens assume uma dimensão educativa vigorosa, em especial, para os adolescentes atraídos para a diversidade de linguagens usadas na produção midiática.

Tendo em vista tais pressupostos, neste artigo busca-se descrever uma intervenção preventivo-educativa a partir de uma reportagem televisiva sobre a legalização da maconha, realizada em um Colégio Estadual da região metropolitana do Estado do Rio de Janeiro. A unidade de ensino tem em seu Projeto Político Pedagógico (PPP) a intenção de desenvolver, com Universidades parceiras, ações educativas relacionadas à promoção da saúde e sensibilização para a redução de danos do uso abusivo de substâncias. Desde 2016, estabeleceu-se parceria entre a escola e o projeto de extensão universitária DESEJA (Drogas, Educação, Saúde e EJA), coordenado pelo GT interinstitucional Educação e Drogas do Grupo Interdisciplinar de Educação, Eletroquímica, Saúde, Ambiente e Arte (GIEESAA/UFRJ/UERJ) ${ }^{135}$.

\section{Metodologia}

Intitulada "Liberação ou não do barato?", a atividade preventivo-educativa foi realizada no Colégio Estadual Professora Antonieta Palmeira (CEPAP), localizada no município de São Gonçalo, bairro Colubandê, no dia 28 de agosto de 2019.

A ação foi centralizada na exibição de reportagem televisiva "Fantástico na Rede Globo mostra realidade do primeiro país a legalizar a maconha Uruguai", de 15min 3s (https://www.youtube.com/watch?v=1Df6KWVAMsM), seguida de debates participativos, realizada em dois momentos: das $16: 30$ às $17: 30 \mathrm{~h}$, com uma turma do nono ano do Ensino fundamental, a 903, e das 18:30 às 19:30, com alunos da NEJA (Nova Educação de Jovens e

\footnotetext{
135 O GIEESAA é coordenado pela professora Dra. Célia Souza (UFRJ) e o GT Educação e Drogas pelos Professores Dr. Francisco Coelho (SEEDUC/RJ) e Maria de Lourdes Silva (UERJ). 


\section{RevistAleph}

Adultos). Com a turma 903, a atividade descrita aconteceu durante as aulas de Ciências naturais e com a NEJA, na disciplina de Biologia.

O primeiro grupo foi composto de 20 alunos e o segundo de 31, em que 15 eram do Módulo II e 16 do IV. A junção das duas turmas foi determinada pelo professor e regente das mesmas, terceiro autor desse artigo. O docente objetivou que todos pudessem vivenciar aquela troca de conhecimentos. A atividade aconteceu no refeitório, equipado com multimídia. $\mathrm{O}$ documentário foi gravado no pendrive da primeira autora e visualizado em um dos laptops da escola, com projeção em datashow.

A heterogeneidade marcou o perfil dos dois grupos. O primeiro, a 903, mais jovem e dentro da faixa etária prevista para este nível de escolaridade (14 anos). Já o segundo, do horário noturno, jovens e adultos, com idades entre 17 e 30 anos, em sua maioria, provedores do lar e com filhos.

A reportagem televisiva foi ao ar dia 13 de setembro de 2015. Três dias depois que o STF (Supremo Tribunal Federal) retomava o julgamento que descriminalizaria o porte da maconha para consumo próprio no Brasil. A sessão ocorreu devido ao recurso de apelação de um egresso do sistema penitenciário que, ainda preso, fora pego com três gramas de maconha na cela. Sentindo-se injustiçado por ter sido condenado com pequena quantidade apelou.

Esse caso aliado à efervescência da campanha pela legalização serviram de base para a pauta do jornalismo do Fantástico, da Globo, que levou equipe de produção para o Uruguai, primeiro país da América Latina a legalizar a maconha. Várias fontes foram ouvidas, desde autoridades da área de segurança pública, da saúde, a psicólogos, empresários brasileiros e uruguaios, que investem no "negócio" da produção da Cannabis sativa. Essas informações, assim pensamos, oferecem dados importantes para que os estudantes conheçam e questionem mais sobre o assunto, por meio de um debate político e legal (COELHO, MONTEIRO, 2017).

Dado tal cenário para a adoção da reportagem como eixo condutor das discussões, adaptamos as propostas de Coelho e Monteiro (2017), considerando: a) ser um audiovisual de fácil acesso, sendo disponibilizado, gratuitamente, no Youtube; b) ser uma produção jornalística de qualidade com variadas fontes para abordar um tema específico; c) partir de 


\section{RevistAleph}

um contexto de legalização factível (e não apenas especulativo), tangendo a realidade de um país vizinho.

Com base nos critérios descritos, buscou-se oferecer aos estudantes olhares de uma outra realidade, estimulando-os para que trouxessem suas experiências e indagações referentes ao que pensam sobre a legalização. Neste sentido, a centralidade da ação foi proporcionar a reflexão acerca das diferenças históricas e sociais entre Brasil e Uruguai e a viabilidade de legalização no Brasil, partindo dos argumentos de legalização oferecidos pelo documentário.

Em ambas as turmas, a atividade foi iniciada com a exposição da proposta e do teor do audiovisual - previamente avisado pelo professor em aulas anteriores, para que os interessados pudessem conhecer mais sobre o assunto. Cabe lembrar que temas polêmicos, sobretudo o assunto drogas, trazem em si a possibilidade de conflitos, dada a divergência de posicionamentos. Esse caminho de oferecer indagações iniciais não impede que outras questões surjam, mas orienta o debate para pontos específicos, como relatam Coelho (2019) e Costa et al. (2019), ao sugerirem a estratégia, sobretudo, na formação de professores.

Para fins deste trabalho, metodologicamente foi observado o impacto da reportagem a partir da observação direta do debate. Para isso observamos dois aspectos ao longo da intervenção: a) como se posicionaram em relação ao tema proposto; e, b) quais os consensos e dissensos em relação à produção jornalística.

\section{Resultados e Discussão}

Buscando um panorama geral, observando o comportamento dos estudantes ao longo do documentário, notamos que o tema mobilizou os dois grupos. Percebeu-se pouca dispersão ao longo da exibição da reportagem, como poucos acessos ao aparelho celular. Convém lembrar que, em ambos os grupos, expressões de incredulidade e curiosidade foram notadas. Esta última aconteceu, por exemplo, no momento que o documentário noticiou que "a maconha era legalizada para os uruguaios e não para os turistas" ou "que, embora legalizada, os usuários só poderiam ter acesso a uma quantidade específica para consumo". Entendemos que essas posturas expressam como os estudantes estavam ancorados em ideias equivocadas de que uma droga legalizada poderia ser usada por qualquer pessoa e em 


\section{RevistAleph}

qualquer quantidade. As expressões dos estudantes revelam o potencial do documentário como como fonte de informação científica, legal e social acerca do tema, reduzindo a desinformação social em torno do assunto (ACSELRAD, 2015; COELHO; ASSIS, BARROS, 2019).

Acerca da primeira questão - como se posicionaram em relação ao tema proposto notou-se que os estudantes da NEJA, parte deles trabalhadores informais ou agentes do lar, carregam estigmas que nutrem falas enraizadas com prejulgamentos. Autores, como Hart (2014) e Acselrad (2015), como visto na introdução do artigo, sinalizam para essa desinformação social que, além de ampliar os tabus, perpetuam pensamentos equivocados. Por outro lado, com a 903, o debate assumiu um contorno mais aberto ao diálogo com assuntos polêmicos. Isso possivelmente ocorreu pois (como relatado por alguns alunos) a questão do uso recreativo ou abusivo de substâncias psicoativas não é algo distante de suas realidades. Substâncias lícitas às ilícitas, como a maconha, integram seus cotidianos, quer por meio da família, quer nos contextos de sociabilidade presenciais ou nas redes sociais.

Cabe lembrar que algumas narrativas da turma 903 foram marcadas pela declaração do uso recreativo da maconha. Após uma das alunas da turma opinar favoravelmente sobre o consumo recreativo e reconhecer-se como usuária recreativa, um colega comentou em tom baixo, mas perfeitamente audível, que se precisassem de alguém que conhecesse a qualidade de maconha que a procurasse. Imediatamente o regente da turma, atento às falas e aos comportamentos, chamou a atenção de todos para que tivessem cuidado com as "brincadeiras" e o tom jocoso. Segundo o professor, comentários inadequados devem ser cortados de imediato, para evitar que, mais adiante, a pessoa seja chamada de "maconheira" e o estigma se alastre. O aluno reconheceu seu erro e desculpou-se com um "foi mal". Situações como essa ocorrem com frequência na sala de aula, rotulando e segregando os usuários via isolamento ou zombaria, evidenciando não apenas a desinformação dos estudantes, como o poder segregador e vexatório de alguns estigmas (HART, 2014; COELHO, 2019).

No tocante ao posicionamento dos grupos em relação ao documentário, observouse, num aspecto geral, forte presença da visão proibicionista que corrobora o medo, com os estigmas, com a mitificação e com prejulgamentos em torno do assunto (HART, 2014; ACSELRAD, 2015; COELHO; MONTEIRO; BARROS, 2017). Em especial na turma 903, embora não se colocassem francamente contrários à legalização da maconha, eles se mostraram mais 


\section{RevistAleph}

atentos às discussões apresentadas na reportagem. Ou seja, pareciam mais compreensivos quanto à política brasileira e com uma possível legalização futura.

Falar sobre essa experiência do país vizinho mostrou-se medida importante para que os jovens desenvolvessem argumentos bem embasados, se contra ou a favor. Observamos que, dentre os estudantes da turma 903, houve quem fizesse comparações entre as realidades dos dois países, tanto de forma cômica (fazendo piadas, como por exemplo, dizendo que iriam ao Uruguai e fingiriam ser cidadãos locais) como de reconhecimento de possíveis avanços para a economia do país com a legalização da planta, tendo reconhecido que tal medida não configura um uso indiscriminado, mas sim regulado.

O grupo da NEJA se revelou mais refratário ao debate, talvez por terem mais experiências dolorosas com o uso de drogas (deles mesmos ou com parentes usuários). Além disso, diferente dos adolescentes da turma 903, se revelaram menos leitores sobre o assunto (principalmente o módulo IV), mostrando-se menos informados que os alunos da turma 903, notadamente. Na NEJA, as impressões favoráveis à legalização da maconha perpassavam por uma postura individualizante ou mesmo meritocrática da questão. Quer dizer, a situação financeira e de vida das pessoas deveriam definir se poderiam fazer uso. Por exemplo, duas alunas do grupo 2, Módulo IV, defenderam que a maconha deveria ser liberada, mas que cabia a cada indivíduo decidir se consumiria ou não (se tivessem dinheiro para tal). Elas fizeram uma comparação entre a liberação da maconha com a de posse de armas no país, em densa discussão. Para as estudantes, essas duas discussões tinham o mesmo peso e consequências, portanto deveriam ter as mesmas responsabilidades. Entretanto, ao se argumentar da possibilidade de uma criança acessar uma arma escondida pelos responsáveis, uma das alunas da NEJA comentou que ela poderia se ferir gravemente, enquanto que se encontrasse um cigarro de maconha, os danos seriam outros, de menor impacto.

A situação anterior evidencia o canal de desinformação social sobre o tema drogas, especificamente sobre a maconha. Esta comparação nos remete a inexistência de discussões sobre o tema nas instituições, quer na família, na escola e nos espaços religiosos, entre outros. Nesse caminho, entendemos que a escola é um espaço potencial para a discussão do tema. Se não tem a oportunidade de pensar sobre o tema, os jovens se enclausuram apenas no que viveram ou ouvem sobre o assunto, por vezes depositando seus discursos nas informações da 


\section{RevistAleph}

internet e nas redes sociais (GOMES. 2018). E isso, acreditamos, pode propagar julgamentos precipitados, sem a dada reflexão.

No que tange aos consensos, parcela dos dois grupos defenderam que o tráfico não iria acabar com a legalização da maconha. Como um negócio que atinge os cinco continentes, obviamente que, a Cannabis é somente mais um dos inúmeros produtos da "relação comercial" e, esta sim, passaria a ser controlada pelo Estado, como apontaram alguns estudantes. $O$ desrespeito ao usuário, em especial, quando pobres e pretos, foi outro aspecto observado pelos estudantes, sem que sequer trouxéssemos essa indagação para o debate. Para eles, há um diferencial no tratamento dado pelas forças de segurança pública que se altera conforme a raça/etnia e classe social. "O playboy é usuário. Já o preto é maconheiro, traficante", sintetizaram.

Acerca das falas raciais mencionadas pelos estudantes, Hart (2014) analisa o peso que a política de raças tem na formação da percepção e nas táticas de combate às drogas, que atingem drasticamente as comunidades pobres, em geral, de minorias étnicas. A boa receptividade à atividade de sensibilização sobre o uso de psicoativos deveria, segundo os estudantes, ser desenvolvido com mais constância. Ao se buscar abrir espaço para o diálogo, conforme preconiza a abordagem de RD, entendemos que essas práticas educativas podem ser o único caminho que alguns estudantes possam ter para ser compreendidos e poderem conversar abertamente sobre o tema, em ambientes mais acolhedores e não condenatórios.

Acerca dos dissensos, merecem destaque os formulados pelo grupo da NEJA. Algo que incomodou a alguns foi a edição do vídeo, com a exibição de ambientes esfumaçados. Criticaram isso, ao entender que nem todo usuário vive em ambientes com tanta fumaça. Reconheceram, assim entendemos, um mito propagado pela película. Para parte dos alunos da NEJA, sobretudo os do módulo IV, o documentário falava das possibilidades econômicas com a Cannabis, o que poderia estimular a comercialização e o uso da planta. Porém, também houve - nos dois grupos - quem sinalizasse a importância do controle estatal sobre a circulação da droga, especialmente com a autorização para plantação da Cannabis sativa. Esse aspecto foi menos citado pelos alunos da 903.

Observamos, a partir de tais relatos, que a introdução de uma matéria jornalística oportunizou o debate qualificado na escola. Ainda que de forma tímida, construiu um espaço de reflexão sobre aspectos que envolvem o tema Cannabis sativa no Brasil e que muitos 


\section{RevistAleph}

estudantes desconheciam. Considerando o curso tempo do documentário e as pontuais dispersões observadas, em nosso entendimento ela se revela como uma ferramenta atrativa, por possuir uma linguagem mais acessível para os estudantes. Mesmo sendo produzida em 2015, seus conteúdos são atuais e curiosos. Com a devida mediação pelo professor, pode proporcionar bons debates emancipatórios.

\section{Considerações finais}

A produção jornalística - radiofônica, impressa, televisiva ou online - é importante ferramenta pedagógica, usada em sala de aula, para estimular a abordagem de temas polêmicos como drogas e, dentre elas, a legalização da maconha. Assim, entendemos que tais intervenções são importantes para oportunizar aos jovens leituras sobre o assunto a partir de suas experiências.

Esse artigo não tema intenção de esgotar os debates sobre a legalização da maconha na escola. Contudo, busca evidenciar como os documentários ou demais audiovisuais, podem ser disparadores de debates que discutam questões sociais mais amplas sobre o uso de drogas. A legalização é apenas um exemplo de como temas polêmicos podem ser tratados na sala de aula e, em hipótese alguma, deve ser confundido com apologia. Trata-se de um pensamento ingênuo e deve ser desconstruído pelo magistério. Obviamente cada turma pode responder ao debate de uma forma. Por isso não vemos essa estratégia do uso do documentário e do debate como uma solução, mas sim como mais um caminho pedagógico para fomentar o senso crítico dos estudantes.

Finalizando, falar sobre a legalização da maconha e outras drogas com os estudantes pode ser visto como um ato de resistência. Resistir no sentido de não ter medo de educar. Resistir a fim de favorecer uma aprendizagem compreensiva da realidade onde os jovens habitam e explorar suas experiências de vida. Resistir para desconstruir mitos acerca do uso da maconha no Brasil, se apropriando dos conhecimentos de países vizinhos. Falar sobre a maconha e de todos os fenômenos legais e científicos associados a ela não é apologia. Tratase de uma real pedagogia. Pedagogia centrada nas bases democráticas e educativas da redução de danos. 


\section{RevistAleph}

\section{Referências:}

ACSELRAD, G. Quem tem medo de falar sobre drogas: Saber mais para se proteger. Rio de Janeiro: FGV, 2015.

BRASIL. Ministério da Educação e do Desporto. Secretaria de Educação Fundamental. Parâmetros curriculares nacionais terceiro e quarto ciclos do ensino fundamental: Saúde. Brasília, DF: MEC/SEF, 1998.

BRASIL. Secretaria Nacional de Políticas sobre Drogas (SENAD). Drogas: cartilha para educadores. Conteúdo e texto original de Beatriz H. Carlini. 2. Ed. Brasília: Ministério da Justiça, SENAD, 2011. 48 p. (Série por dentro do assunto)

BRASIL. ANVISA. Regulamentação: Resolução sobre produtos de Cannabis entra em vigor. Publicado em 09 de março de 2020. Disponível em: http://portal.anvisa.gov.br/noticias/-

/asset_publisher/FXrpx9qY7FbU/content/resolucao-sobre-produtos-de-cannabis-entra-emvigor/219201. Acesso em: 03 mai. 2020.

CASTRO, M. C.; MELO, B.; BORTOLINI, R. A comunicação invade a escola! RJ: BEM TV - Educação e Comunicação: 2007.

COELHO, F. J. F. Educação sobre Drogas e Formação de professores: uma proposta de ensino a distância centrada na Redução de Danos. 245f. Tese (Doutorado) - Instituto Oswaldo Cruz, PósGraduação em Ensino em Biociências e Saúde. Rio de Janeiro, 2019.

COELHO, F. J. F.; ASSIS, T. S.; BARROS, M. D. M. Proposta Pedagógica para Utilização do Filme Bicho de Sete Cabeças na Perspectiva da Saúde Mental e Redução de Danos do Uso Abusivo de Drogas. REnCiMa, v. 10, n.5, p. 301-317, 2019.

COELHO, F. J. F.; MONTEIRO, S. Educação sobre drogas: um olhar transversal rumo à democracia. In: IX Seminário Internacional Redes Educativas e Tecnologias. Rio de Janeiro, 6, 2017, Rio de Janeiro. Anais... Rio de Janeiro: Universidade do Estado do Rio de Janeiro, 2017. Disponível em: http://www.seminarioredes.com.br/ixredes/adm/trabalhos/diagramados/TR311.pdf. Acesso em: 04 mai. 2020.

COELHO, F. J. F.; MONTEIRO, S.; BARROS, M. D. M. Papo Aberto sobre a Cannabis: O uso de Charges como estratégia educativa para estimular debates sobre drogas nas aulas de Ciências e Biologia. In: Encontro Regional de Ensino de Biologia da 4a Regional Uberlândia/MG. Uberlândia, 24 a 26 de agosto de 2017, Uberlândia. Anais... Universidade Federal de Uberlândia, 2017. Disponível em: http://educacaosobredrogas.com.br/wp-content/uploads/2018/05/Papo-aberto-sobreCannabis.pdf. Acesso em: 03 mai. 2019.

COSTA, V. M.; COELHO, F. J. F.; TAMIASSO-MARTINHON, P.; SOUSA, C. Projeto DESEJA: da gênese às adaptações educativas para a formação de jovens multiplicadores sobre saúde e drogas em Duque de Caxias, RJ. In: COELHO, F. J. F.; TAMIASSO-MARTINHON, P.; SOUSA, C. (org.). Educação em Ciências, Saúde e Extensão Universitária. 1.ed. Curitiba: Brazil Publishing, 2019.

FANTÁSTICO. Fantástico na Globo mostra a realidade do primeiro país a legalizar a maconha Uruguai. Fantástico da Globo. Postado em 13 set. 2015. Disponível em: https://www.youtube.com/watch?v=1Df6KWVAMsM. Acesso em: 04 mai. 2020. 


\section{RevistAleph}

GOMES, G. S. Sobre as notícias falsas - fake news: uma análise a partir das redes sociais e aplicativos de comunicação digital. Revista Jurídica do Ministério Público do Tocantins. Palmas: CESAF, ano 11, no 16, 2018. pp. 156-173.

HART, C. Um preço muito alto. 1. Ed. Rio de Janeiro: Jorge Zahar, 2014.

MALACHIAS, R. NEINB, T. Experiências de Formação de Professoras(es) na Diáspora. Questões Pedagógicas e Metodológicas. Práticas Educomunicativas na Implementação da Lei 10.639/03. In: Colóquio Internacional O Ensino da História e Cultura da África e da Diáspora - 9 - 12 Novembro de 2009, Brasília.

PENHA, E. M.; CARDOSO, D. D .S.; COELHO, L. P.; BUENO, A. M. A regulamentação de medicamentos derivados da Cannabis sativa no Brasil. In: Brazilian Journal of Forensic Sciences, Medical Law and Bioethics. 9(1):125-145 (2019).

SOARES, I. Educomunicação, didática e razão de ser. Entrevista na Revista Ensino Superior. Disponível em: https://revistaensinosuperior.com.br/educomunicacao-didatica-e-razao-de-ser/. Acesso em: 04 mai. 2020.

SILVA, M. L. Drogas: Da medicina à repressão policial - a cidade do Rio de Janeiro entre 1921 e 1945. Rio de Janeiro: Outras Letras, 2015.

Data do envio: $28 / 02 / 2020$

Data do aceite: 10/06/2020. 